Industrial Health, 1977, 15, 123.

\title{
EXPERIMENTAL INFECTIVE PNEUMOCONIOSIS: EFFECT OF CANDIDA ALBICANS AND IRON ORE DUST ON THE LUNGS OF GUINEA PIGS
}

\author{
Sibte H. ZAIDI, Ramkrishna S. DOGRA, Anand P. SAHU, \\ Santosh KHANNA and Ravi SHANKER
}

\author{
Industrial Toxicology Research Centre, Mahatma Gandhi Marg, \\ Lucknow-226001, India
}

(Received April 4, 1977)

\begin{abstract}
Guinea pigs inoculated intratracheally with Candida albicans, a facultative pathogen of upper respiratory tract of miners, and iron ore dust did not produce extensive pulmonary fibrosis and the reaction chiefly consisted of thickened interalveolar septa at the termination of experiment (180 days). The poor fibrogenic response observed has been suggested to be the inhibitory effect of possibly the soluble fraction of iron ore on the growth of $C$. albicans.
\end{abstract}

The role of chronic pulmonary infection like tuberculosis in dusty occupations has focussed much attention on the fibrogenic potential of mine dust. Many cases of progressive massive fibrosis have been described in hematite ore miners. ${ }^{1 \sim 3)}$ Earlier studies from our centre have pointed out the importance of other chronic low grade infections in the augmentation of pulmonary lesions caused by dusts.,5) The present experiments were, therefore, conducted in guinea pigs injected intratracheally with iron ore dust mixed with a facultative pathogen (Candida albicans) of the upper respiratory tract of miners.

\section{Materials AND Methods}

Iron ore dust was obtained from the Director, National Metallurgical Laboratory, Jamshedpur (Bihar). The required fine dust $(<5 \mu \mathrm{m}$ particle size) was prepared and the chemical analysis revealed $98.1 \%$ ferric oxide, $0.66 \%$ silica and other oxides of aluminium, magnesium and calcium were present in traces. A weighed quantity of dust was suspended in physiological saline solution to obtain a final concentration of $50 \mathrm{mg} / \mathrm{m} l$. The solution was autoclaved at $15-\mathrm{lb}$ pressure for $20 \mathrm{~min}$.

The organism-Candida albicans (Robin) Berkh. was obtained from the Antibiotics Division, Central Drug Research Institute, Lucknow. The suspension of organims for inoculation into guinea pigs was prepared from a 48-hr-old culture grown on Sabouraud's agar medium and dose was same as described earlier.4)

Ninety female guinea pigs of an average $300 \mathrm{~g}$ body weight were obtained from the 
I.T.R.C. animal house colony and maintained on pellet diet (Hindustan levers), green leafy vegetables and water ad libitum. The animals were then divided into three groups and inoculated intratracheally as follows according to method described earlier. ${ }^{6)}$

No. of animals

Group I $\quad 30 \quad$ Iron ore dust $-75 \mathrm{mg}$ in $1.5 \mathrm{ml}$ sterile physiological saline per animal.

Group II $\quad 30 \quad$ Iron ore dust $-75 \mathrm{mg}$ and $500 \mu \mathrm{g}$ organism in $1.5 \mathrm{~m} l$ sterile physiological saline per animal.

Group III $\quad 30 \quad$ Organism- $500 \mu \mathrm{g}$ in $1.5 \mathrm{~m} l$ sterile physiological saline per animal. This group is the same as the control group previously described.4)

Two animals from each group were killed under the ether anaesthesia and autopsied immediately after inoculation. The rest of the animals were killed and autopsied at intervals of $1,7,15,30,60,90,120,150$ and 180 day after inoculation.

After removing the cardiac lobe, the remaining lung tisssue was gently distended to normal size with 10\% formol saline. After preliminary fixation blocks were selected along the long axes of both the lungs to include the maximum area for study. The fixation was completed with fresh fixative, blocks embedded in paraffin and cut at $5 \mu \mathrm{m}$. Multiple sections from each block were stained with hematoxylin and eosin, silver impregnated,") Periodic Acid Schiffs-Hematoxylin for organisms. ${ }^{8)}$ Pathological grading of fibrosis was assessed. ${ }^{9}$ The viable count of the organisms from the cardiac lobe of the lung was made as described earlier. ${ }^{4)}$

\section{Results}

The animals which received iron ore alone (Group I) showed, on macroscopic examination of lungs, patchy congestion at early periods; subsequently it involved whole of the lobe at 30 days. However, at later periods focal areas of congestion were seen. In group II small dark-pink colored patches were encountered at early periods. There was, however, no significant lesion towards the termination of experiment.

\section{Group I}

Immediately after the inoculation of iron ore the lungs on microscopic examination presented varying amounts of dust particles in the tubules from bronchioles to alveoli, which caused marked degree of congestion, oedema and slight hemorrhage at 1 day. In addition, there was moderate polymorphonuclear leucocytic reaction together with congested septal capillaries especially in the areas of dust deposition. The bronchi and bronchioles contained plugs of cellular exudate admixed with dust and oedematous fluid. By 7 days the acute inflammatory reaction almost subsided and the small dust aggregates lay in the alveolar lumen with little cellular reaction, while the interalveolar septa continued to exhibit increased cellularity. At subsequent periods there appeared moderate phagocytosis of dust particles which formed isolated aggregates of dust cell reacton together with infiltration of lymphocytes. 
EXPERIMENTAL INFECTIVE PNEUMOCONIOSIS

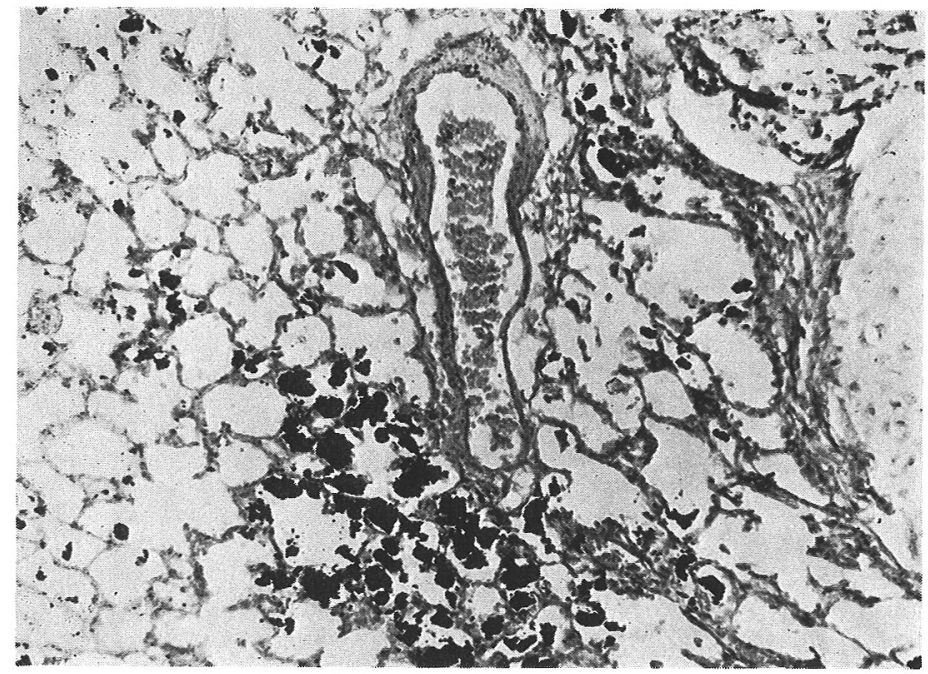

Fig. 1.

Iron ore alone, 120 days. Focal dust collections in paravascular areas. Hematoxylin and Eosin. $\times 195$.

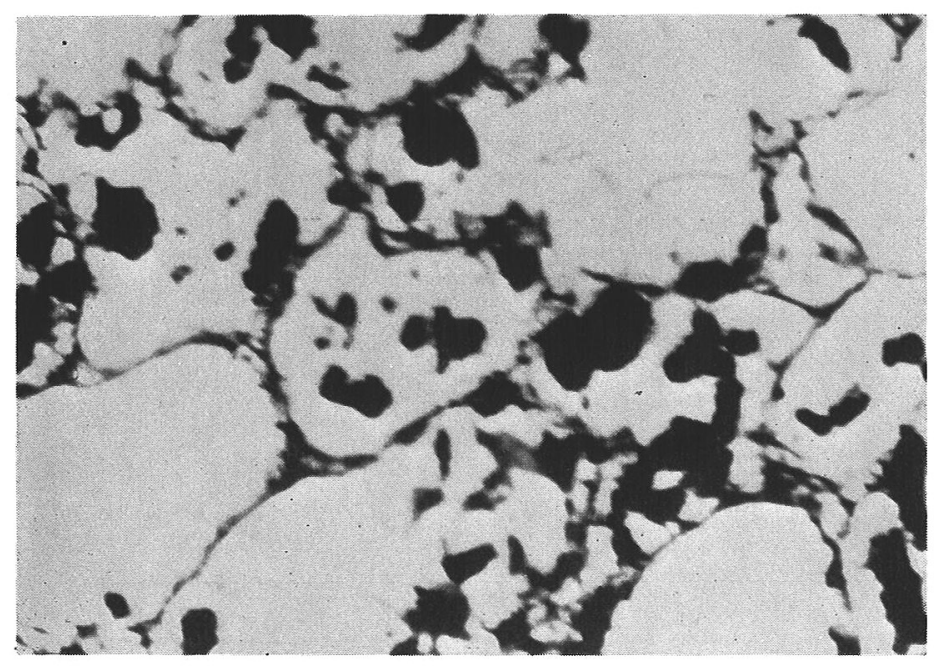

Fig. 2.

Iron ore alone, 180 days. No fibrosis. Silver impregnation. $\times 780$.

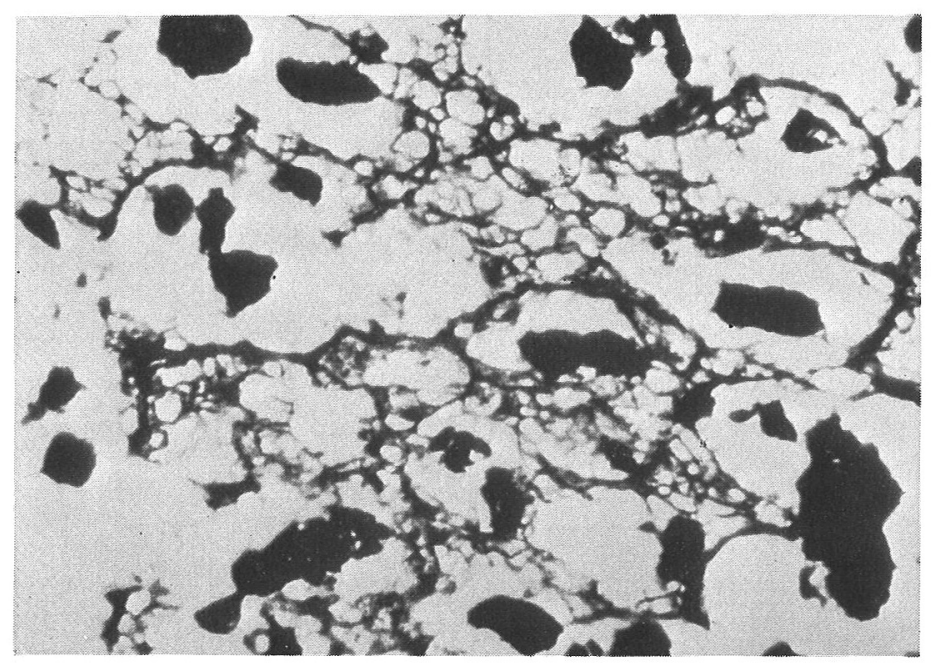

Fig. 3 .

Iron ore and C. albicans, 180 days. Thickened interalveolar septa. Silver impregnation. $\times 780$. 


\section{EXPERIMENTAL INFECTIVE PNEUMOCONIOSIS}

There was hardly any progress of dust reaction till 120 days except that a few small focal dust collections also developed in the paravascular areas without any fibrotic reaction (Fig. 1.) However, at the termination of experiment (180 days) the iron ore dust lay in the varying sized clumps in alveolar lumen with little fibroblastic reaction like an inert dust. Silver impregnation revealed occasional reticulin fibres in the area of dust deposition (Fig. 2).

\section{Group II}

Soon after the intratracheal inoculation of iron ore dust and organisms, there was an irregular distribution of dust particles and organism (PAS-positive) in different parts of the lung parenchyma. Acute inflammatory reaction was seen at 1 day. However, at 7 days a few foci of dust particles together with some mononuclear cells were encountered in the parenchyma and the alveolar lumen appeared quite patent. By 15 days the interalveolar septa revealed moderate thickening due to accumulation of dust particles, macrophages and lymphocytes. By 30 days a distinct paravascular aggregation of dust particles began in addition to lymphoid hyperplasia. The reaction at 60 days comprised of proliferation of fibroblasts in the area of dust deposition. Consequently at later periods the dust formed larger foci involving many alveoli filled with dust-laden macrophages together with moderate increase in the fibroblastic reaction. The dust filled alveoli in the vicinity of bronchioles, however, developed adenomatoid change at 120 days, which further involved alveolar ducts by 150 days. In addition, there was marked lymphoid hyperplasia in the vicinity of bronchioles and blood vessels.

The fibrotic reaction at the termination of experiment (180 days) was in the form of thickened interalveolar septa in the areas of dust deposition (Fig. 3).

The viable count of the organisms became negative by 15 days after intratracheal inoculation.

\section{Discussion}

Pulmonary lesions of varying degree in workers associated with exposure to iron ore during mining and other iron and steel industrial operations have been described.10 12) However, it has been reported that quite often the miners got exposed to a mixture of iron and silica dust. ${ }^{13,14)}$ Mineral from different sites had different composition of silica and of different biological activity. ${ }^{15)}$ In the present study after the intratracheal inoculation of iron ore dust in guinea pigs the dust particles initially caused an acute inflammatory reaction in the lung parenchyma which subsequently subsided. The dust particles then got phagocytosed and aggregates formed in the alveolar lumen interspersed with slight cellular response. This confirmed the work reported earlier. ${ }^{16 \sim 18)}$ The development of paravascular deposits of iron dust at later periods accompanied by little fibroblastic proliferation resembled the reaction provoked by an inert dust. ${ }^{19)}$ Perhaps the silica contents in the present sample were too small to cause any reaction. 


\section{S.H. ZAIDI et al.}

Acute inflammatory reaction due to Candida albicans infection has been described in lungs of guinea pigs. ${ }^{20,21)}$ Earlier studies from our centre have shown that when $C$. albicans was injected into the lungs of guinea pigs there appeared acute inflammatory reaction in the early stages and by 90 days the infection got cleared off. At later periods the only evidence of pulmonary candidiasis was in the form of slight lymphoid hyperplasia.4)

In the present studies the combined effect of iron ore dust and C.albicans infection in the lungs of guinea pigs was in the form of thickened interalveolar septa in the area of dust deposition at 180 days. From 15 days onwards the viable counts of organisms became negative and there was not much progress in the pulmonary reaction. However, the moderate difference seen between group I (Iron ore alone) and group II (Iron ore plus C. albicans) could presumably be due to synergistic action of dust and infection in the latter group. It seems quite possible that the growth of organisms in the lungs might have been inhibited either due to adsorption on the particulate form of dust or its soluble form. Many inorganic ions and metals are known to affect profoundly the production by bacteria of toxins, pigments, antibiotic substances and antigens. ${ }^{22}$ Further the inhibitory effects of iron upon the toxin production by Corynebacterium diphtheriae have been reported by many workers. $\left.{ }^{23} 27\right)$ Unlike the influence of C. albicans infection in the augmentation of pulmonary fibrotic lesions caused by amosite or manganese dust in guinea pigs, $\left.{ }^{4}, 5\right)$ the combined effect of iron ore dust and C. albicans in the present study did not produce extensive fibrotic lesions.

How far soluble fraction of iron dust inhibited the growth of C. albicans or counteracted the fibrogenic factor(s) released by organism needs further work.

\section{ACKNOWLEDGEMENTS}

This investigation was supported by a grant from the United States Government of Health, Education and Welfare, Public Health Service of Public Law 83-480 to which the authors are grateful.

The authors are thankful to Mr. M.M. Lal for the preparation and chemical analysis of dust, to Mr. Lalji Shukla and Mr. S.N. Srivastava for technical assistance and to Mr. Musleh Ahmad for photomicrography.

\section{REFERENCES}

1) Stewart, M.J. and Faulds, J.S. (1934). J. Pathol. Bacteriol., 39, 233.

2) Dunner, L. (1943). Brit. J. Radiol., 16, 287.

3) Harding, H.E. and Massie, A.P. (1951). Brit. J. Ind. Med., 8, 256.

4) Zaidi S.H., Dogra, R.K.S., Shanker, R. and Chandra, S.V. (1973a). Environ. Res., 6, 287.

5) Zaidi, S.H., Shanker, R. and Dogra, R.K.S. (1973b). Environ. Res., 6, 274.

6) Zaidi, S.H. (1969). Experimental Pneumoconiosis, p. 33. Johns Hopkins Press, Baltimore.

7) Gordon, H. and Sweets, H.H. Jr. (1936). Am. J. Pathol., 12, 545. 


\section{EXPERIMENTAL INFECTIVE PNEUMOCONIOSIS}

8) Winner, H.I. and Hurley, R. (1964). Candida albicans, p. 180. J. \& A. Churchill Ltd. London.

9) Belt, T.H. and King, E.J. (1945). Spec. Rep. Ser. Med. Res. Coun. (Lond.) No. 250, p. 29.

10) Faulds, J.S. (1975). J. Clin. Pathol., 10, 187.

11) Dorshenko, V.V. (1970). Gig. Tr. Resp. Mezhaved. SB., 6, 214.

12) Boyd, J.T. and Doll, R. (1970). Brit. J. Prev. Soc. Med., 51, 63.

13) McLaughlin, A.I.G. and Harding, H.E. (1956). Arch. Ind. Health, 14, 350.

14) Buckup, H. (1970). Z. Gesamte Hyg. Grenzgeb., 16, 479.

15) Tokmurzina, R.U. and Dzhangozina, D.M. (1970). Gig. Tr. Prof. Zabol., 14, 51.

16) Naeslund, C. (1938). J. Ind. Hyg. Toxicol., 20, 435.

17) Vorwald, A.J., Pratt, P.C., Durkan, T.M., Delahant, A.B. and Bailey, D.A. (1950). Ind. Med. Surg., 19, 170.

18) Byers, P.D. and King, E.J. (1961). J. Pathol., 81, 123.

19) Gross, P. (1964). Health Phys., 10, 995.

20) Urso, B. and Capocaccia, L. (1952). Arch. Ital. Sci. Med. Trop., 33, 313.

21) Vogel, R.A. and Krehl, W. (1957). Am. Rev. Tuberc., 76, 692.

22) Wilson, G.S. and Miles, A.A. (1964). Topley and Wilson's Principles of Bacteriology and Immunity, 5th ed., Vol. I. p. 87. Edward Arnold Ltd. London.

23) Locke, A. and Main, E.R. (1931). J. Infect. Dis., 48, 419.

24) Pope, C.G. (1932). Brit. J. Exp. Pathol., 13, 218.

25) Pappenheimer, A.M. Jr. and Johnson, S.J. (1936). Brit, J. Exp. Pathol., 17, 335.

26) Edwards, D.C. and Seamer, P.A. (1960). J. Gen. Microbiol., 22, 705.

27) Barksdale, L. (1970). Bacteriol. Rev., 34, 378. 